\title{
Poder Judicial de la Federación
}

Tanto la Suprema Corte de Justicia de la Nación (SCJN), el máximo tribunal del país, como los tribunales federales, han emitido resoluciones sobre temas de derecho internacional y sobre el control de convencionalidad. En seguida algunas resoluciones sobre estos temas:

\section{TESIS AISLADAS}

\section{Primera Sala}

Rubro: TORTURA. GRADOS DE VIOLACIÓN DEL DERECHO A LA INTEGRIDAD FÍSICA Y PSÍQUICA DE LAS PERSONAS.

Esta tesis refiere que, de acuerdo con la jurisprudencia de la Corte Interamericana de Derechos Humanos, la violación al derecho a la integridad física y psíquica tiene diversas connotaciones de grado. ${ }^{1}$

Rubro: DeReChOS humanos. SU CONTENIDO NO SE LIMITA AL TEXTO EXPRESO DE LA NORMA QUE LO PREVÉ, SINO QUE SE EXTIENDE A LA INTERPRETACIÓN QUE LOS ÓRGANOS AUTORIZADOS HAGAN AL RESPECTO.

Esta tesis sostiene que, los derechos humanos se robustecen con la interpretación evolutiva o progresiva que hagan tanto los tribunales constitucionales nacionales, como intérpretes últimos de sus normas fundamentales, así como con la interpretación que hagan los organismos internacionales, intérpretes autorizados en relación con tratados específicos, en una relación dialéctica. ${ }^{2}$

1 Tesis 1a. LVI/2015, Gaceta del Semanario Judicial de la Federación, Décima Época, febrero 2015, p. 1423.

2 Tesis 1a. CDV/2014, Gaceta del Semanario Judicial de la Federación, Décima Época, t. I, noviembre de 2014, p. 714. 
Esta revista forma parte del acervo de la Biblioteca Jurídica Virtual del Instituto de Investigaciones Jurídicas de la UNAM www.juridicas.unam. $\mathrm{mx}$

2. Tribunales Colegiados de Circuito

Rubro: "SOFT LAW". LOS CRITERIOS Y DIRECTRICES DESARROLLADOS POR ÓRGANOS INTERNACIONALES ENCARGADOS DE LA PROMOCIÓN Y PROTECCIÓN DE LOS DERECHOS FUNDAMENTALES SON ÚTILES PARA QUE LOS ESTADOS, EN LO INDIVIDUAL, GUÍEN LA PRÁCTICA Y MEJORAMIENTO DE SUS INSTITUCIONES ENCARGADAS DE VIGILAR, PROMOVER Y GARANTIZAR EL APEGO IRRESTRICTO A LOS DERECHOS HUMANOS.

Esta tesis hace referencia a que la normatividad internacional no sólo puede limitarse, por parte de los agentes del Estado mexicano, en la aplicación de las normas vinculantes sino que también debe admitirse el desarrollo de principios y prácticas de derecho internacional de carácter no vinculante. También se menciona que tal criterio de observancia del soft law, no tendría como consecuencia desconocer el principio de subsidiariedad de las normas supranacionales ni la inobservancia del orden jurídico nacional. ${ }^{3}$

Rubro: Ministerio PÚblico. Las DiReCtRices SObRe La FUnCiÓn DE LOS FISCALES APROBADAS POR EL OCTAVO CONGRESO DE LAS NACIONES UNIDAS SOBRE PREVENCIÓN DEL DELITO Y TRATAMIENTO DEL DELINCUENTE, CELEBRado en la Habana (CUba) del 27 de agosto al 7 DE SEPTIEMbre de 1990 (“SOFT LAW"), SON PARÁMETROS ÚTILES PARA MEJORAR LAS PRÁCTICAS EMPLEADAS POR AQUÉL EN SU FUNCIÓN INVESTIGADORA, CON BASE EN EL PRINCIPIOS DE OPORTUNIDAD.

Esta tesis hace mención del soft law, a diferencia de la anterior que lo aborda en lo general, sobre el derecho penal: los agentes ministeriales del Estado mexicano deben tomar sus decisiones con base en el principio de oportunidad en la protección de los derechos humanos de los imputados y de las víctimas u ofendidos, adoptando, además de la normatividad doméstica, el soft law cuando se protejan los mismo bienes jurídicos. ${ }^{4}$

3 Tesis XXVII. 3o. 6 CS, Gaceta del Semanario Judicial de la Federación, Décima Época, t. III, marzo de 2015, p. 2507.

4 Tesis XXVII. 3o. 11 P, Gaceta del Semanario Judicial de la Federación, Décima Época, t. III, marzo de 2015, p. 2432. 
Esta revista forma parte del acervo de la Biblioteca Jurídica Virtual del Instituto de Investigaciones Jurídicas de la UNAM

\section{TESIS JURISPRUDENCIALES}

Rubro: JURISPRUdenCIA DE LA SUPREMA CORTE DE JUSTICIA DE LA NACiÓN. NO ES SUSCEPTIBLE DE SOMETERSE A CONTROL DE CONSTITUCIONALIDAD.

Esta tesis jurisprudencial es relevante para el sistema jurídico nacional ya que plantea la cuestión de si es posible inaplicar, al realizar un control de constitucionalidad y/o convencionalidad ex officio, la jurisprudencia de la Suprema Corte de Justicia de la Nación (SCJN). La respuesta de la SCJN es que no es posible aplicar ningún control; el fundamento está en el artículo 94 constitucional que establece que será obligatoria para todos los órganos jurisdiccionales y en el artículo 217 de la Ley de Amparo. Y concluye: "aun partiendo del nuevo modelo de interpretación constitucional, no es posible determinar que la jurisprudencia del Máximo Tribunal del país pueda ser objeto de la decisión de un órgano de menor grado que tienda a inaplicarla... porque permitirlo daría como resultado que perdiera su carácter de obligatoria, ocasionando falta de certeza y seguridad jurídica”.

Elaborado por Mónica Elizabeth Nuño Nuño

5 Tesis P./J. 64/2014, Gaceta del Semanario Judicial de la Federación, Décima Época, t. I, diciembre de 2014, p. 8 . 